$2016-12-15$

\title{
Utilization of harmonics current in single phase system
}

\author{
al-bayaty, Hussein
}

http://hdl.handle.net/10026.1/10545

10.1109/ICHQP.2016.7783468

Proceedings of International Conference on Harmonics and Quality of Power, ICHQP IEEE

All content in PEARL is protected by copyright law. Author manuscripts are made available in accordance with publisher policies. Please cite only the published version using the details provided on the item record or document. In the absence of an open licence (e.g. Creative Commons), permissions for further reuse of content should be sought from the publisher or author. 


\section{Utilization of Harmonics Current in Single Phase System}

\author{
Hussein Al-bayaty \\ School of Computing, Electronics \\ and Mathematics \\ University of Plymouth, UK \\ Hussein.al-bayaty@plymouth.ac.uk \\ kabily30@gmail.com
}

\author{
Marcel Ambroze \\ School of Computing, Electronics \\ and Mathematics \\ University of Plymouth, UK \\ M.Ambroze@plymouth.ac.uk
}

\author{
Mohammed Zaki Ahmed \\ School of Computing, Electronics \\ and Mathematics \\ University of Plymouth, UK \\ M.Ahmed@plymouth.ac.uk
}

\begin{abstract}
This paper presents a simple method to benefit of the harmonics current which is produced on the source side because of the nonlinear loads in single phase systems. The proposed circuit contributes in reduction of the total harmonic distortion (THD) and draw harmonics current via low pass filter (LPF) and create a useful power by rectifying the distorted current via full wave bridge rectifier (convert it to $\mathrm{DC}$ current) and reconvert it to $\mathrm{AC}$ sinusoidal current by using single phase inverter controlled by PWM circuit in order to feed different loads. The circuit has been designed and simulated in the MATLAB-Simulink program.

It can be concluded from the results of the simulation, that the utilized current $\left(I_{u}\right)$ can be created by rectifying harmonics current $I_{h}$ with simple design and low cost circuit without requiring any additional current drawn from the source and can feed RL-load.
\end{abstract}

\section{KEYWORDS}

Harmonics Elimination, Passive Filters, Total Harmonic Distortion (THD)

\section{INTRODUCTION}

The harmonic distortion is very old phenomenon though it has been discovered since 19th century. The main issue at that time was the effect of harmonics on the electric machines and the interference with telephone lines. However, the invention of power electronics devices and variable frequency drives (VFD) has created big concerns and serious problems for public utilities, distribution systems and the customers[1].

Different methods have been used to eliminate harmonics current from the power system [2] [3] [4]. Due to its simplicity of design, simplicity of control, low cost and variety of types, passive filter is one of the most popular methods. However, its depends on the principle of providing low impedance path through $X_{L}$ (for low frequencies) and low impedance through $X_{C}$ (for high frequencies) in order to take out the harmonic current and grounding it [5]. for huge power systems, if the total harmonic distortion (THD) and then the total harmonics current have been calculated in every subsystem, then it can be concluded that the system loses every day hundreds of harmonics current in total by grounding it.

In example, if we have a power supply with non-linear load draws fundamental current $\left(I_{1}=70 \mathrm{~A}\right)$ and harmonics current $\left(I_{h}=20 \mathrm{~A}\right)$, so the supply has to feed total supply current $\left(I_{t}\right.$
$=72.8 \mathrm{~A})$ because $\left(I_{t}^{2}=I_{1}^{2}+I_{h}^{2}\right)$ and THD $=28 \%$. In this case the useful current is $I_{1}$ and the lost current which going to be grounded is $I_{h}$. The idea of taking benefit of harmonics current can invest $20 \mathrm{~A}$ (in this case), as a free power can feed different loads by using conventional methods (rectifier and inverter or active front end).

\section{HARMONICS UTILIZATIONS}

Researchers tried to invest the harmonics phenomenon through using it in some applications in order to address some problems, such as:

1) Islanding Detection: Islanding detection has many negative effects on the power grid [6]. According to [7], Islanding can be detected by measuring the harmonics which have been generated by the over modulating inverter.

2) Power Exchanger in DPFC: One of the components within the flexible AC-transmission system (FACTS) family, is Distributed Power-Flow Controller (DPFC). DPFC has used third-harmonic frequency as an active power exchanger between the shunt and series converters instead of the common DC link [8], [9].

3) Identifying of Problems: Harmonics measurement and an on-line analysis of the system's harmonics, may be necessary to properly identify the cause of some problems and recommend solutions. This usually involves a harmonic analysis of the current or voltage waveforms observed in the electrical system [10].

4) Improving Inverter Utilization: Harmonic injection enables an improvement in the DC bus utilization for the multiphase voltage source inverter (VSIs) without moving into the over-modulation region, while still providing sinusoidal output phase voltages [11] [12].

5) Losses Reduction Method: The authors in [13] propose to add a third harmonic to the PWM reference signal to alter the harmonic spectrum of sinusoidal PWM inverters and thus reduce motor losses.

6) Reuse the harmonic current in three phase system: The authors in [14] [15] presented a new idea to reuse the harmonics via proposing a new topology of three phase passive filter [14] and a new topology of three phase 
hybrid active power filter (HAPF) [15]. However, these topologies are still complex in design as represent three phase system.

This article presents the idea of utilizing harmonics current and reuse it to feed different loads via using passive filter and active front end with simpler design in single phase system.

Firstly, the methodology has been presented and a schematic diagram has been designed, secondly, the circuit has been investigated and tested via Matlab-Simulink program, finally, the results have been assessed through comparing the results in three cases.

\section{System Description (Methodology)}

A simplified schematic of the circuit is shown in the figure (1), the circuit consists of a single phase $220 \mathrm{~V}$ AC voltage source connected in series with low pass side of the passive (LC) filter (100 $\mathrm{mH}$ inductor) and in parallel (but not grounded) with high pass side ( $0.1 \mathrm{mF}$ capacitor). This capacitor will take out all harmonics current (over $50 \mathrm{~Hz}$ ) passes it into the new proposed utilization circuit (consists of full wave bridge rectifier and 4-pulses inverter). The output current is sinusoidal current and can be used to feed different electrical loads.

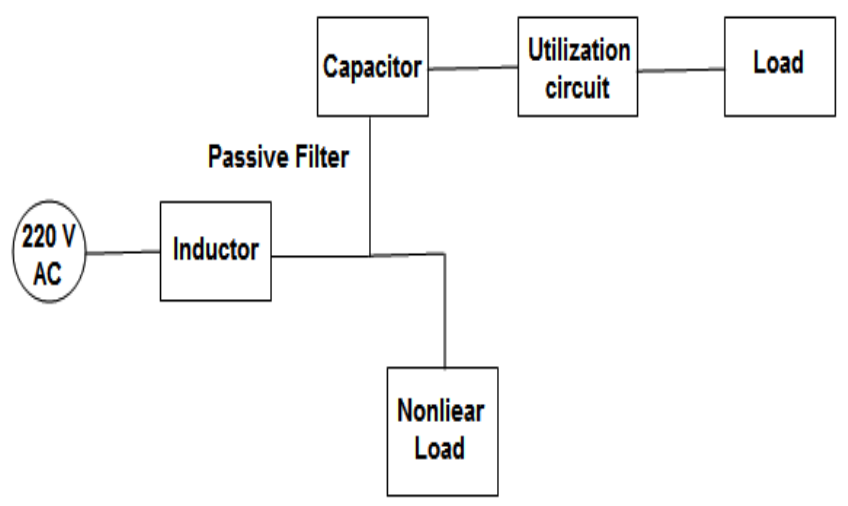

Fig. 1. Schematic diagram

\section{CAses to Study}

The following three cases will show the differences in results between a circuit with nonlinear load and the same circuit with conventional LPF and the same circuit with different topology of LPF with the active front end. The results and figures have been collected and classified to make a comparison between these cases in the following items :

1) First case: AC power supply $220 \mathrm{v}$ with nonlinear load (a single diode with RL-load) produces $T H D_{I}=43.35$ $\%$, without use of any filter as shown below in figure 2 : $T H D_{I}$ and $T H D_{V}$ can be changed with size and type of the nonlinear load.

2) Second case: In addition to the same circuit (in figure 2) a conventional low pass filter (LPF) will be connected in series with $\mathrm{L}$ and in parallel with $\mathrm{C}$ and a small resistor in order to measure the harmonics current as it is shown in the figure 3 .

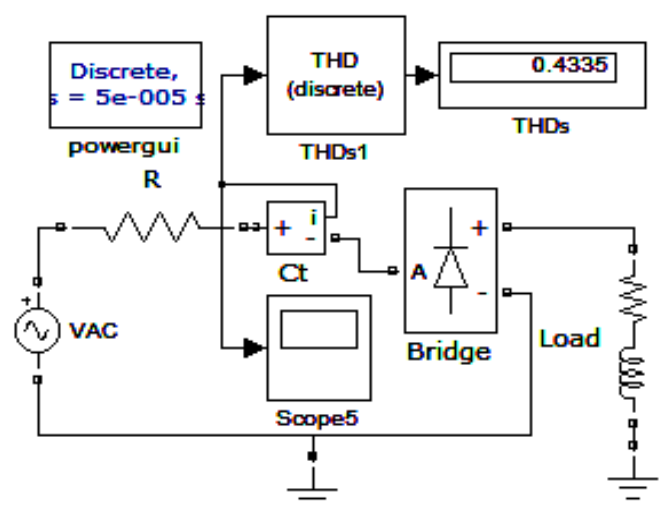

Fig. 2. First case circuit

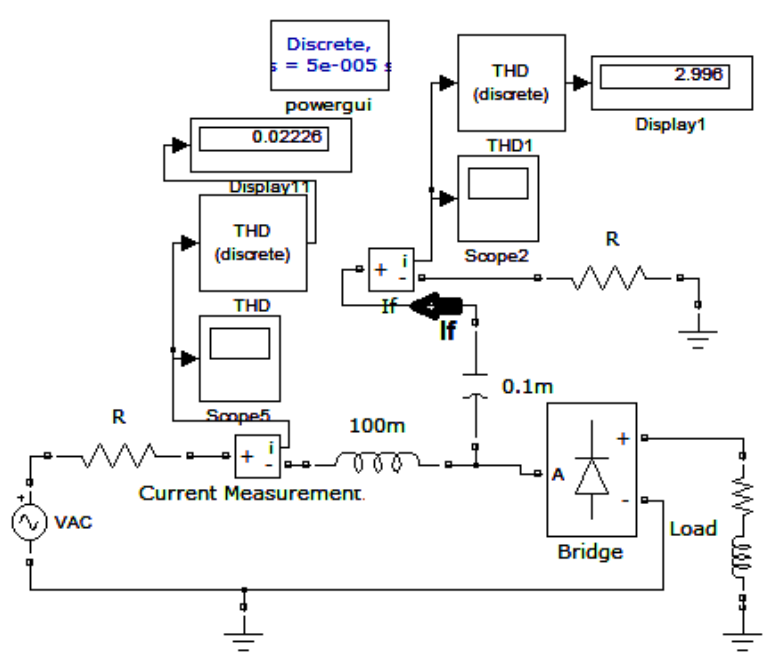

Fig. 3. Second case circuit

THD $D_{I}$ is decreased into $2.2 \%$, the source current $I_{s}$ is $7.2 \mathrm{~A}$, and filter current $I_{f}$ (in the capacitor branch) is 2.1 A (distorted current) $T H D_{I}=300 \%$. Figure 4 shows the filter current waveform or the extracted harmonics current in the case of using LPF.

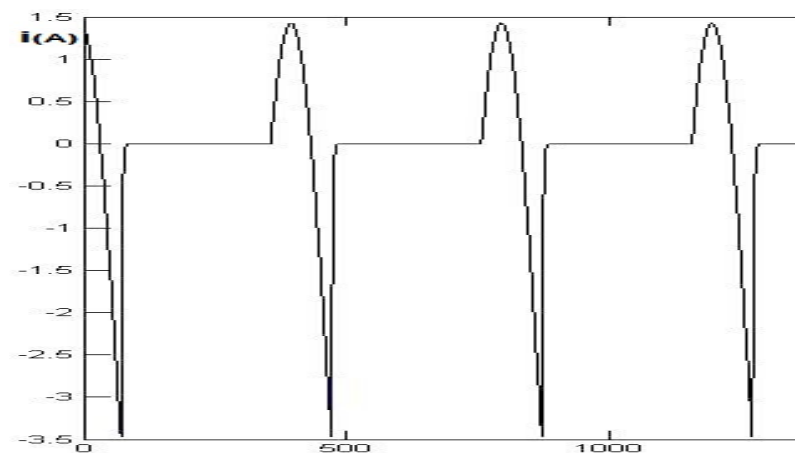

Fig. 4. Filter current in the second case

3) Third case: The same circuit (as fig. 3) has been connected in addition to the utilization circuit in fig. 5 . 


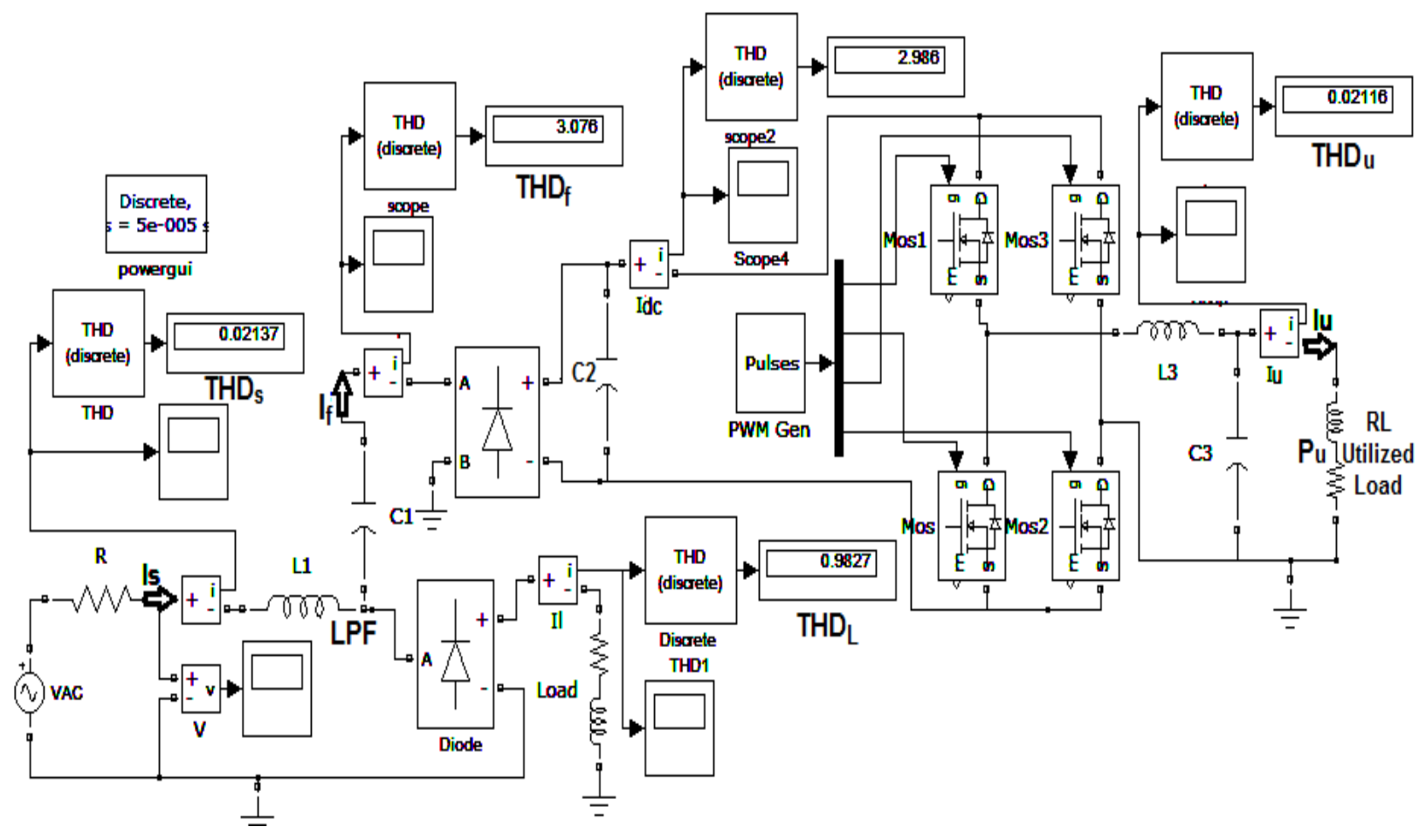

Fig. 5. Third case circuit

The utilization circuit consists of a bridge rectifier with four pulses single phase inverter controlled by PWM circuit, the inverter is connected to RL-load as a utilized load. The capacitor $C_{2}$ after the bridge rectifier has been used as a dc voltage storage, and its value can be chosen as $1.1 \mathrm{mF}$ or higher depending on the load current, voltage and on the required value of $T H D_{u}$. The source current $I_{s}$ in figure 6 has $T H D_{s}=2.2 \%$. The output utilized current waveform $I_{u}=1.4 \mathrm{~A}$ is sinusoidal as shown in figure 6, with very low $T H D_{I}=1.7 \%$ and the source current $I_{s}$ still 7.2 A without any extra current drawing.

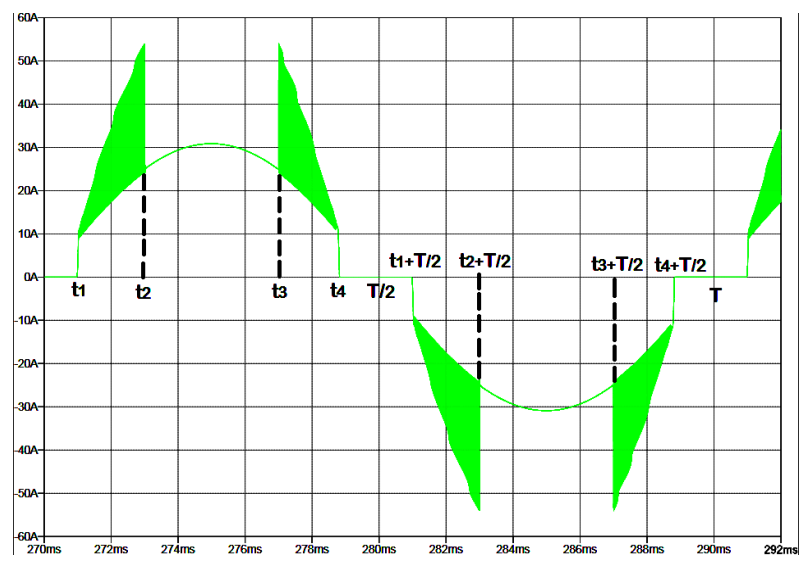

Fig. 6. Source current in the 3 rd case

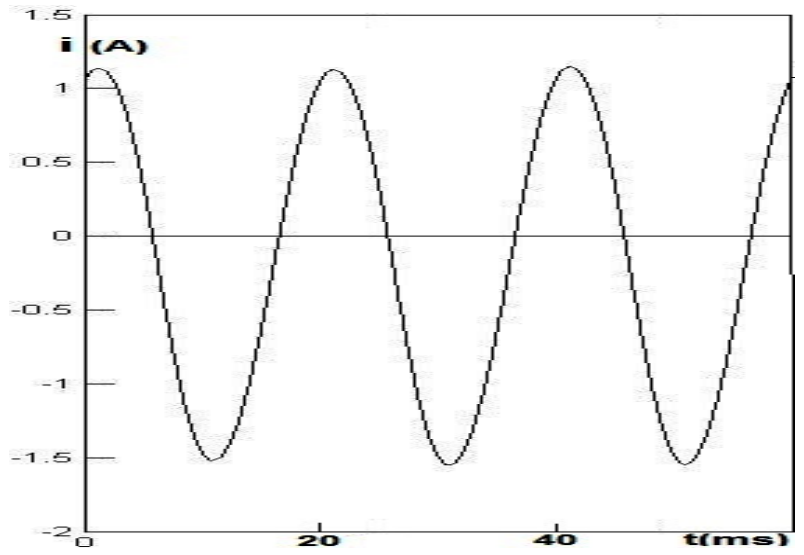

Fig. 7. Utilization current $I_{u}$ waveform

\section{Vi. Simulation Results Assessment}

This study required three cases to study and compare results of each case. The first case shows a single phase voltage source in series with a single diode and inductive load as a nonlinear load. In this case $T H D_{I}=43.35 \%$ without using any filter.

The second case is the same circuit adding a conventional LPF with $\mathrm{L}=100 \mathrm{mH}, \mathrm{C}=0.1 \mathrm{mF}$ and tuning frequency $=$ $50 \mathrm{~Hz}$. THD $_{I}$ of the source has decreased to $2.2 \%$ and the source current $\left(I_{s}\right)$ in this case is $7.2 \mathrm{~A}$, while the harmonic current or filter current $\left(I_{f}\right)$ at the high frequency (capacitor) branch is highly distorted as shown in figure 4.

The third case shows the full circuit adding a utilization circuit consisting of full wave bridge rectifier and single phase 
inverter controlled by PWM circuit in series with the utilized load (RL-load). $I_{s}$ and $I_{h}$ remained at the same value, however a new current will appear on the output of inverter, which is the utilized current $I_{u}=1.4$ A that feeds RL-load. This $I_{u}$ current has been created from the rectification of the harmonics current into sinusoidal current with just $T H D_{I}=1.7 \%$ at the load side.

The table below displays the values of $I_{s}, I_{u}$, distortion of the source $\left(T H D_{s}\right) \&$ distortion of the filter $\left(T H D_{f}\right)$ which change against specific values of $\mathrm{L}$ and $\mathrm{C}$ choosing in a way that investigate the $50 \mathrm{~Hz}$ tuning frequency for LPF but in different filter impedances.

\begin{tabular}{|c|c|c|c|c|c|c|}
\hline & $\mathrm{L}(\mathrm{m})$ & $\mathrm{C}(\mathrm{m})$ & $I_{s}$ & $I_{u}$ & $T H D_{s}$ & $T H D_{f}$ \\
\hline Case 1 & 0 & 0 & 110 & 0 & 43.3 & 0 \\
\hline Case 2 & 100 & 0.1 & 7.2 & 0 & 2.2 & 289 \\
\hline Case 3 & 100 & 0.1 & 7.2 & 1.4 & 1.7 & 305 \\
\hline Case 3 & 50 & 0.2 & 21 & 4 & 3.2 & 246 \\
\hline Case 3 & 18 & 0.56 & 38 & 13.7 & 5.6 & 180 \\
\hline Case 3 & 10 & 1 & 61 & 22 & 8.8 & 164 \\
\hline Case 3 & 1 & 10 & 123 & 43 & 27 & 133 \\
\hline Case 3 & 0.5 & 20 & 149 & 67 & 51 & 126 \\
\hline
\end{tabular}

The first row shows the big value of $\left(\right.$ THD $\left._{s}=43.35 \%\right)$ in the first case, because the use of nonlinear load without adding any filter.

The second row shows that the value of $I_{s}$ has decreased into 7.2 AC ampere, and $T H D_{s}$ decreased to $2.2 \%$ with very high THD $_{f}=289 \%$ on the capacitor's branch of LPF because the capacitor offers low impedance $X_{C}$ in high frequencies and isolate the harmonics current from the source. These values reflect the effectiveness of the LPF to draw the harmonics current.

The 3rd, 4th, 5th, 6th, 7th \& 8th rows show the values of $I_{s}$, $I_{u}, T H D_{s} \& T H D_{f}$ in the third case when using a utilizing circuit in six different values of $\mathrm{L}$ and $\mathrm{C}$ which tunes the LPF's frequency at the $50 \mathrm{~Hz}$ fundamental frequency.

Figure 8, presents the values of $\mathrm{L} \& \mathrm{C}$ against filter impedance $\left(Z_{f}\right)$ in the $3 \mathrm{rd}$ case. It shows that the filter impedance $Z_{f}$ directly proportion with inductance value and inversely with capacitance value of LPF.

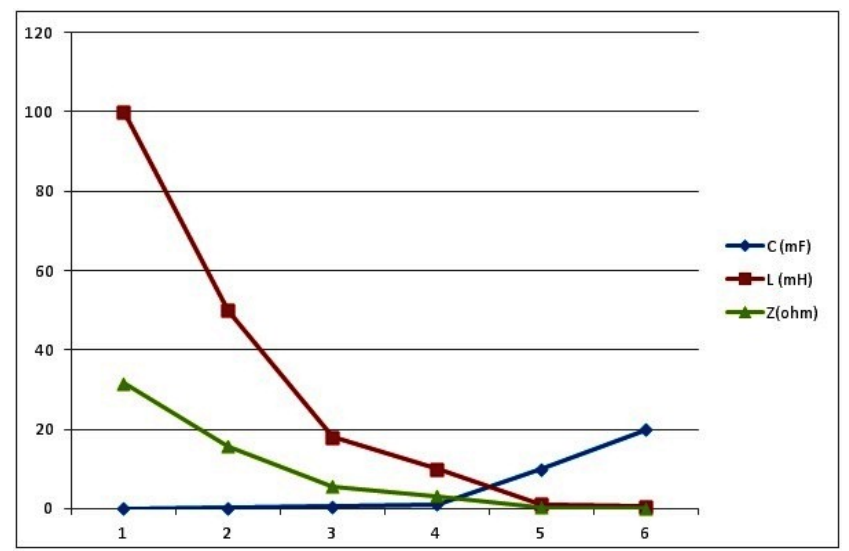

Fig. 8. The values of $\mathrm{L} \& \mathrm{C}$ against filter impedance
Figure 9, shows a comparison between $T H D_{s} \& T H D_{f}$ in six different values of filter impedance of the 3 rd case. The values of $\left(T H D_{s}\right)$ is increasing and the values of $\left(T H D_{f}\right)$ is decreasing. Therefore, it can be concluded that the LPF decreased its ability to draw harmonics when (C) is increasing and $(\mathrm{L})$ and $\left(Z_{f}\right)$ is decreasing.

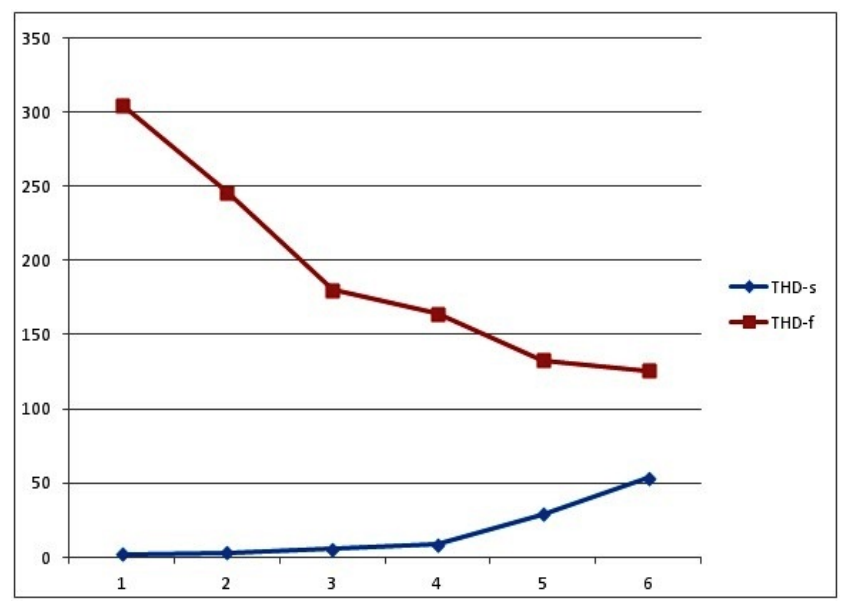

Fig. 9. Comparison between $T H D_{s} \& T H D_{f}$ in six values of $\mathrm{L} \& \mathrm{C}$

On the other hand, figure 10 shows a comparison between $I_{s}$ and $I_{u}$ values in the 3 rd case and proves that $I_{s}$ and $I_{u}$ are directly proportional with $\mathrm{C}$ Value and inversely with $\mathrm{L}$ and $Z_{f}$ values. This phenomenon means that, the low impedance LPF will cost the source additional current but in the same time, will produce additional $I_{u}$ after utilization circuit.

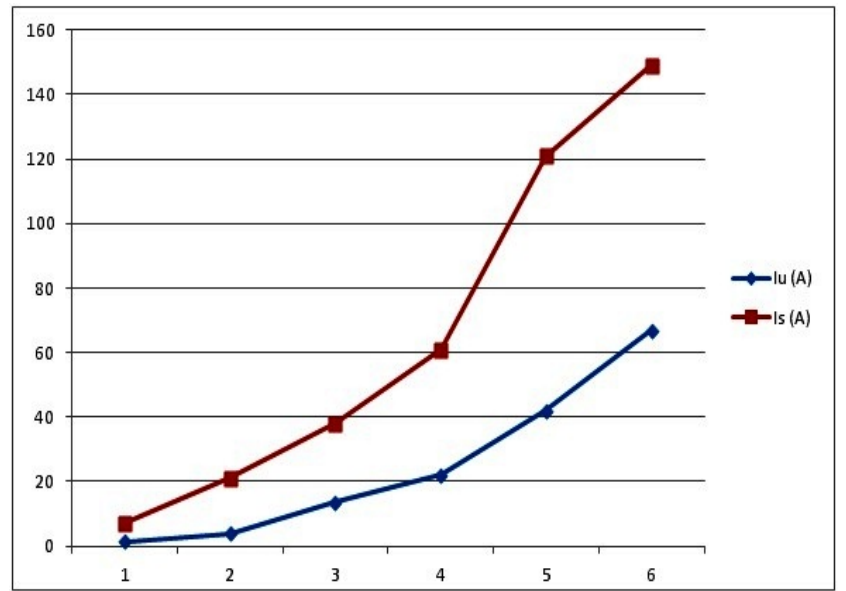

Fig. 10. Comparison between $I_{s} \& I_{u}$ in 6 values of $\mathrm{L} \& \mathrm{C}$

The chosen value of impedance filter $Z_{f}=31.6 \Omega$ in the third row, when $\mathrm{L}=100 \mathrm{mH}$ and $\mathrm{C}=0.1 \mathrm{mF}$ is the optimum value for this circuit, because it does not require additional source current and can get a sinusoidal $I_{u}=1.4 \mathrm{~A}$ on the output. 


\section{CONCLUSION}

This article presented a simple design of LPF using a simple method in order to utilize harmonics current in single phase systems by filtering out the harmonics current $I_{h}$ via LPF and passing it through a utilization circuit (consists of full wave bridge rectifier and 4-pulses inverter controlled by PWM circuit) in order to rectify the distorted current $I_{h}$ into sinusoidal current called $I_{u}$ and feed different loads.

Three cases have been assessed and compared using Matlabsimulink program. It can be concluded from the results of the simulation, that the utilized current $I_{u}$ can be created by rectifying harmonics current $I_{h}$ with a simple cost and without requiring any additional source current $I_{s}$ and a simple RLload can be fed by $I_{u}$.

\section{REFERENCES}

[1] C. Francisco, Harmonics and power systems. CRC press, 2006.

[2] B. Wu, S. Rizzo, N. Zargari, and Y. Xiao, "An integrated dc link choke for elimination of motor common-mode voltage in medium voltage drives," in Industry Applications Conference, 2001. Thirty-Sixth IAS Annual Meeting. Conference Record of the 2001 IEEE, vol. 3, Sept 2001, pp. 2022-2027 vol.3.

[3] J. Persson, "Comparing harmonics mitigation techniques," 2014.

[4] J. Rodriguez, J. Pontt, R. Huerta, and P. Newman, "24-pulse active front end rectifier with low switching frequency," in Power Electronics Specialists Conference, 2004. PESC 04. 2004 IEEE 35th Annual, vol. 5. IEEE, 2004, pp. 3517-3523.

[5] A. Nassif, W. Xu, and W. Freitas, "An investigation on the selection of filter topologies for passive filter applications," Power Delivery, IEEE Transactions on, vol. 24, no. 3, pp. 1710-1718, July 2009.

[6] A. Massoud, K. Ahmed, S. Finney, and B. Williams, "Harmonic distortion-based island detection technique for inverter-based distributed generation," Renewable Power Generation, IET, vol. 3, no. 4, pp. 493507, 2009.

[7] S.-I. Jang and K.-H. Kim, "An islanding detection method for distributed generations using voltage unbalance and total harmonic distortion of current," Power Delivery, IEEE Transactions on, vol. 19, no. 2, pp. 745752, 2004.

[8] Z. Yuan, S. de Haan, and B. Ferreira, in Power Electronics and Applications, 2007 European Conference on, Sept, pp. 1-4.

[9] Z. Yuan, S. de Haan, J. Ferreira, and D. Cvoric, "A facts device: Distributed power-flow controller (dpfc)," Power Electronics, IEEE Transactions on, vol. 25, no. 10, pp. 2564-2572, Oct 2010.

[10] J. J. Toth and D. J. Velazquez, "Benefits of an automated on-line harmonic measurement system," Industry Applications, IEEE Transactions on, vol. IA-22, no. 5, pp. 952-963, Sept 1986.

[11] A. Iqbal, E. Levi, M. Jones, and S. Vukosavic, "Generalised sinusoidal pwm with harmonic injection for multi-phase vsis," in Power Electronics Specialists Conference, 2006. PESC'06. 37th IEEE. IEEE, 2006, pp. $1-7$.

[12] J. Jose, G. Goyal, and M. Aware, "Improved inverter utilisation using third harmonic injection," in Power Electronics, Drives and Energy Systems (PEDES) \& 2010 Power India, 2010 Joint International Conference on. IEEE, 2010, pp. 1-6.

[13] J. Boys and S. Walton, "A loss minimised sinusoidal pwm inverter," in IEE Proceedings B (Electric Power Applications), vol. 132, no. 5. IET, 1985, pp. 260-268.

[14] H. Al-bayaty, M. Ambroze, and M. Z. Ahmed, "Taking advantage of the harmonics at the load side using passive filters," in Systems and Informatics (ICSAI), 2014 2nd International Conference on, Nov 2014, pp. $169-174$.

[15] active power filter," in 2015 IEEE 5th International Conference on Power Engineering, Energy and Electrical Drives (POWERENG), May 2015, pp. 330-336. 